\title{
CLINICAL EFFECTIVENESS OF LUMBAR EPIDURAL INJECTION FOR SPINAL DISC HERNIATION: A RANDOMISED CONTROL TRIAL.
}

\footnotetext{
1. MRCS (Eng) FEBOT, FRCS (Tr \& Orth)

Epsom \& St Heliers Hospital NHS Trust.

2. FCPS (Orth), FEBOT, FRCS (Tr \& Orth) Assistant Professor Department of Orthopaedic and Trauma Surgery

Lady Reading Hospital Medical Teaching Institute.
}

Correspondence Address:

Dr. Umar Zia Khan

Assistant Professor

Department of Orthopaedic and

Trauma Surgery

Lady Reading Hospital, Peshawar 25000

drumarzia@gmail.com

Article received on: 28/05/2018

Accepted for publication:

$15 / 11 / 2018$

Received after proof reading:

25/06/2019

\begin{abstract}
Athar M Siddqui ${ }^{1}$, Umar Zia Khan²
ABSTRACT... Lumbar epidural is an established procedure, which is commonly used to control pain in cases of disc herniation secondary to lumbar disc disease. We conducted the present study to evaluate the clinical effectiveness of lumbar epidural injection using image intensifier comparing to injection using loss of resistance technique with no fluoroscopy. We also evaluated the outcome of these patients with patients treated conservatively with opioid or other analgesia as a control group. Study Design: Prospective randomized controlled trial. Setting: Epsom General Hospital, an elective part of Epsom \& St Helier's University Hospital spine services. Period: April 2015 and October 2015. Materials and Methods: Single center, after seeking appropriate ethical approval in our institution. Group allocation for loss of resistance and II was done by list schedulers independent to the knowledge of trial, operating list become available to research team on the day of procedure. Results: Fifty-five patients were included in each group. A single clinician performed all procedures and the same combination of local anaesthetic and steroid were injected in all patients. Preoperative and postoperative visual analogue score (VAS) and Oswestry Disability Index (ODI) were obtained for each patient. Conclusions: There is a better outcome demonstrated in both injection groups when compared with control. The post-operative scores did not statistically differ significantly between fluoroscopic and loss of resistance groups. The final results of this trial question the efficacy and cost effectiveness of epidural injections using image intensifier and may be used as a reference to change the current practice within several hospitals as cost saving measure. Level of Evidence: 1.
\end{abstract}

Key words: $\quad$ Disc Herniation, Epidural Injection, Fluoroscopy, Loss of Resistance, Lumbar Spine.

Article Citation: Siddqui AM, Khan UZ. Clinical effectiveness of lumbar epidural injection for spinal disc herniation: a randomised control trial. Professional Med J 2019; 26(7):1108-1115. DOI: 10.29309/TPMJ/2019.26.07.3777

\section{INTRODUCTION}

Lumbar epidural injection is one of the most commonly used methods to reduce pain and improve functional status following lumbar disc herniation for radiculopathy and back pain the effectiveness of which is well established, especially short termed, within the literature..$^{1-4}$ There has been heavy focus on the accuracy of the epidural injections with fluoroscopy in terms of needle placement rates as compared to those using the loss of resistance technique with none or little discussion and analysis of the clinical effectiveness of the two epidural techniques in form of patient pain control and functional status. ${ }^{5-7}$

The aim of this research study is to compare outcomes in three groups of patients with regards to pain control and functional status at three months after application of the lumbar epidural injection using both fluoroscopy and loss of resistance techniques and a control group with expectant therapy.

\section{METHODOLOGY}

This study involves a randomised, double-blind control trial of patients treated with lumbar epidural injections both with and without image guidance. This was conducted in Epsom General Hospital, an elective part of Epsom \& St Helier's University Hospital spine services. The study was initially registered as an audit in the hospital's audit department with ethics approval for clinical trial been obtained later. 


\section{Participants}

All respondent patients that participated in the study belong to a single consultant. All patient respondents were informed about the trial we were conducting either pre operatively, on the day of their injection or at 3 months follow up. Verbal consent was taken from all the patients that participated in this study.

\section{Inclusion \& Exclusion Criteria}

Patients with low back and lower extremity pain with function limiting intensity for more then 8 weeks with single or multiple level disc herniation with clinical radiculopathy correlating to the level of nerve root impingement were included. Patients with previous spinal surgeries in form of lumbar inter body fusion, neurogenic claudication, facet joint hypertrophy causing nerve root impingement were excluded. Minimum age of inclusion was 18 years. Patients with unstable psychiatric illness, history of opioid or alcohol abuse, pregnant or lactating women, known allergies to local anesthetics or steroid were also excluded.

We created three groups of patients from April 2015 to October 2015 each comprising 55 patients. Two of them randomized by the elective list schedulers independent of the knowledge of the clinician completing the list and the patients, for lumbar epidural injection with or without fluoroscopy, for completion the schedulers were unaware of the trial as well. Both lists were conducted under the same consultant (clinician) one with and the other without fluoroscopy guidance to overcome inter-observer variability and both groups were injected with similar strength and amount of local anaesthetic and steroid combination. The third group of 55 controlled group included patients who wanted to opt for expectant therapy using day to day pain relief in form of analgesia (either opioid or anti inflammatory) as appropriate for their level of pain.

Pre treatment numeric rating scale of pain and functional status in form of Oswestry Disability Index is been recorded prior to injection or at first clinical appointment in case of control group, pre treatment employment status and use for opioid or other form of analgesia also noted for comparison at 12 weeks for all three groups two types of epidural techniques fluoroscopic and non-fluoroscopic and no treatment.

\section{Description of Interventions}

A single surgeon, in sterile operating theatre, treated all patients who required lumbar epidural injections. Most of the time patients were in right or left lateral position with few expectations dictated by body habitus or other theatre factors (operating table height or convenience for image intensifier usage) were then done prone under sedation with standard preparations.

\section{Lumbar Epidural Injection using Loss of Resistance Technique}

Following $5 \mathrm{ml} 0.5 \%$ Marcaine local anaesthetic infiltration around proposed area 16 or 18 gauge toughy needle was inserted 15 degrees caudal angulation advancing just below the interlaminar gap towards superior lamina aspect with continuous or intermittent pressure as appropriate was applied on the syringe plunger. The syringe was then taken off to ensure that there was no dural tap. Cocktail $(20 \mathrm{ml}$ using $0.25 \%$ bupivacaine $3 \mathrm{ml}+80 \mathrm{mg}$ methyl prednisolone non-particulate $2 \mathrm{ml}+15 \mathrm{ml}$ normal saline to dilute solution in case of accidental spinal) were injected slowly over a period of 5 to 10 minutes to avoid post injection headache.

\section{Lumbar Epidural Injection using Image Intensifier}

For patients being treated with epidural under Image Intensifier or fluoroscopy, the initial preparation and procedure was similar to that detailed above. In addition to this, once needle position was confirmed both anterior posterior (AP) and lateral images were taken, on satisfactory needle position confirmation 5 to $6 \mathrm{ml}$ of Omnipaque (lohexol) $240 \mathrm{mg} / \mathrm{ml}$ contrast within the epidural space was injected under direct fluoroscopic observation to ensure distribution within epidural space. After confirmation, cocktail as mentioned above was injected.

\section{Co-Interventions}

There is no other intervention offered in forms of occupational therapy or bracing. Physical 
therapy and day-to-day opioid or other form of analgesia was used in each group including expectant therapy group was arranged through their respected General Practitioner.

\section{Intra or Post Operative Complications}

There is no intra or post operative complication in all 110 patients comprising both loss of resistance and Image Intensifier group either immediately or at 3 months follow up in form of any immediate headache, infection, bleeding, dural tap or nerve injury.

\section{Sample Size}

The sample sizes for each of the groups was pre-determined in light of previously conducted studies and statistical power calculations. A total of 165 patients, with 55 patients in each of the three groups, with a two-tailed confidence level of $95 \%$ and power of $80 \%$ was required and subsequently used for this study.

\section{Patient Outcomes}

The patients were divided into three groups according to the treatments that they were given. Group A included patients treated using lumbar epidural injections with fluoroscopy; Group B comprises those treated with lumbar epidural injections using the loss of resistance technique; and the third group is a control group which were not given any lumbar epidural injections. Each of the three groups was assessed at both baseline and a pre-defined interval of 3 months. The two main outcome methods utilised in this study include the Visual Analogue Scores (VAS) for pain and the Oswestry Disability Index (ODI). Changes in employment or working status were used as a secondary means of measuring improvements in patient condition. For the purposes of this study, a patient was regarded as a success where there was significant relief measured in terms of either the VAS for pain or the ODI at 3 months. Significant was considered to be at least a $50 \%$ decrease in pain from baseline condition.

\section{Statistical Methods}

Visual Analogue Scores of pain and Oswestry Disability Indices for the patients were measured and tabulated at both baseline and 3 months. Data comparison and analysis was conducted utilising average calculations, for mean and mode, and standard deviations. Z-scores and subsequent $\mathrm{p}$-values for the data were calculated. A p-value of less than 0.05 was regarded statistically significant and a p-value of less than 0.001 was considered highly statistically significant.

\section{RESULTS}

\section{Patient Flow}

A schematic presentation of patient flow from baseline to 3 months is shown in Figure-1 below.

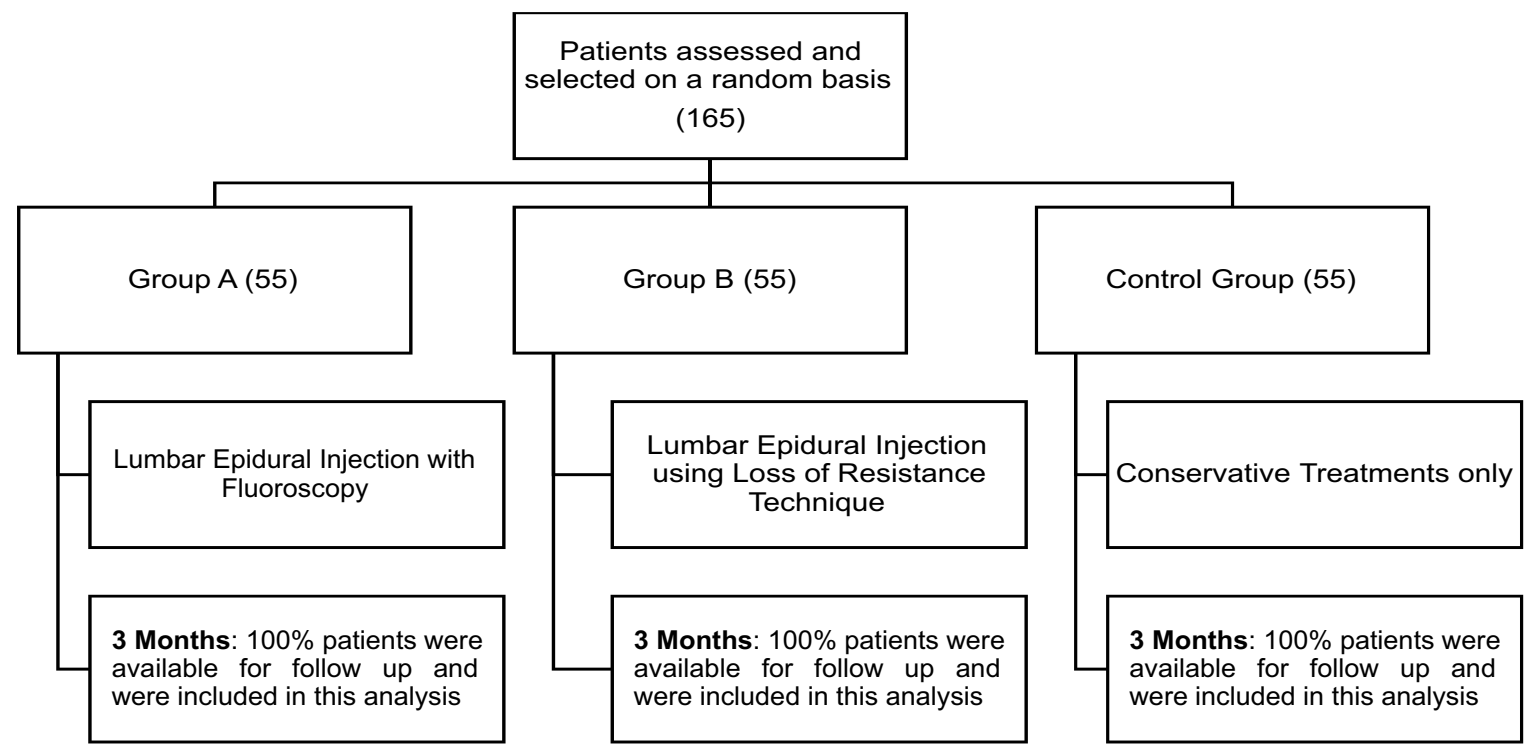

Figure-1. Patient flow at baseline and 3 months 


\section{Baseline Demographic and Clinical Profile of Patients}

Baseline demographic and clinical characteristics of patients in each of the three groups have been tabulated as follows:

\section{Comparison of Visual Analogue Scores for}

\section{Pain for 3 Months}

A comparison of VAS for pain involved a basic analysis of mean VAS for pain at baseline and three months for each of the three groups as shown in Table-lla followed by an evaluation of patients with significant pain relief and average relief per group as shown in Figure-2 and Table$\mathrm{Ilb}$, respectively.

\begin{tabular}{|c|c|c|c|c|}
\hline & & $\begin{array}{c}\text { Group A } \\
\text { (55) }\end{array}$ & $\begin{array}{c}\text { Group B } \\
\text { (55) }\end{array}$ & $\begin{array}{c}\text { Control Group } \\
\text { (55) }\end{array}$ \\
\hline \multirow{2}{*}{ Gender } & Male & $49.09 \%(27)$ & $49.09 \%(27)$ & $50.91 \%(28)$ \\
\hline & Female & $50.91 \%(28)$ & $50.91 \%(28)$ & $49.09 \%(27)$ \\
\hline Age & Mean \pm SD & $63.12 \pm 19.85$ & $57.51 \pm 20.05$ & $58.91 \pm 21.92$ \\
\hline \multirow{2}{*}{ Employment Status } & Employed & $38.18 \%(21)$ & $40.00 \%(22)$ & $36.36 \%(20)$ \\
\hline & Not Employed & $61.82 \%(34)$ & $60.00 \%(33)$ & $63.64 \%(35)$ \\
\hline Visual Analogue Score & Mean \pm SD & $7.45 \pm 0.98$ & $7.45 \pm 1.02$ & $7.68 \pm 1.01$ \\
\hline Oswestry Disability Index & Mean \pm SD & $44.38 \pm 14.64$ & $48.48 \pm 12.04$ & $49.52 \pm 12.91$ \\
\hline \multicolumn{5}{|c|}{ Table-I. Baseline demographic and clinical profile of patients } \\
\hline & & $\begin{array}{c}\text { Group A } \\
\text { (55) }\end{array}$ & $\begin{array}{c}\text { Group B } \\
\text { (55) }\end{array}$ & $\begin{array}{c}\text { Control Group } \\
\text { (55) }\end{array}$ \\
\hline Baseline & Mean \pm SD & $7.45 \pm 0.98$ & $7.45 \pm 1.02$ & $7.68 \pm 0.13$ \\
\hline 3 Months & Mean \pm SD & $3.91 \pm 2.36^{1}$ & $4.40 \pm 2.57^{2}$ & $5.61 \pm 0.32$ \\
\hline
\end{tabular}

Figure-2. Patients with significant pain relief in terms of visual analogue score for pain

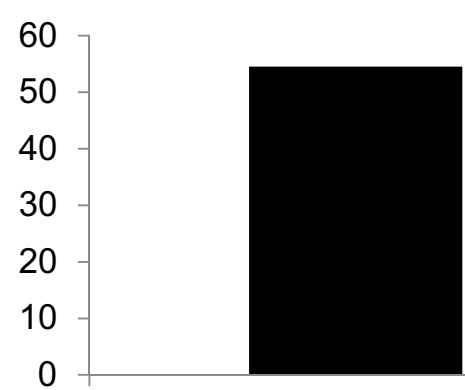

Group A

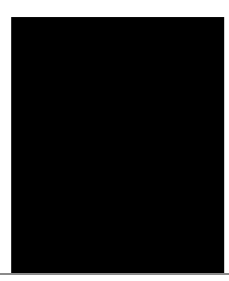

Group B

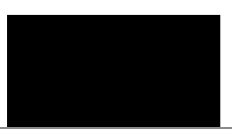

Control Group

Patients with Significant Pain Relief

\begin{tabular}{|c|c|c|}
\hline $\begin{array}{c}\text { Group A } \\
\mathbf{( 5 5 )}\end{array}$ & $\begin{array}{c}\text { Group B } \\
\mathbf{( 5 5 )}\end{array}$ & $\begin{array}{c}\text { Control Group } \\
\mathbf{( 5 5 )}\end{array}$ \\
\hline 30 & 25 & 11 \\
\hline $54.55 \%$ & $45.45 \%$ & $20.00 \%$ \\
\hline
\end{tabular}


For the purposes of Table-llb, successful patients were regarded as those with at least $50 \%$ pain relief. In interpreting the results tabulated above, a higher score shows greater improvement in patient condition. The findings show that Group $B$ had highest mean relief among successful patients, with a VAS for pain of 5.72. The control group had both, the lowest success rate for patients with significant relief, and lowest average relief rates amongst both successful and failed patients.

\section{Comparison of Oswestry Disability Indices for 3 Months}

An analysis of the findings pertaining to the Oswestry Disability Indices amongst patients involved an evaluation of the mean ODI values for each of the three groups at baseline and 3 months as shown in Table-Illa. This is followed by comparing the proportion of patients with significant pain relief and an analysis of average relief per group in terms of the ODI for each group in Figure-3 and Table-IIIB, respectively.

\section{Comparison of Employment Characteristics for 3 Months}

A comparison of employment characteristics for 3 months was used as a secondary means of assessing improvement in patient outcomes. For the purposes of Table-IV, patients were divided into the following categories: employed; unemployed (due to pain); housewife; and retired (over 65). The findings have been tabulated as follows:

\begin{tabular}{|c|c|c|c|c|}
\hline & \multirow[b]{2}{*}{ Mean \pm SD } & Successful Patients & Failed Patients & Total \\
\hline Group A & & $5.40 \pm 1.22$ & $1.32 \pm 1.38$ & $3.55 \pm 2.42$ \\
\hline Group B & Mean \pm SD & $5.72 \pm 1.79$ & $0.83 \pm 1.18$ & $3.05 \pm 2.86$ \\
\hline Control Group & Mean \pm SD & $5.23 \pm 1.60$ & $0.45 \pm 1.29$ & $2.19 \pm 2.59$ \\
\hline \multicolumn{5}{|c|}{ Table-Ilb. Average relief per group in terms of visual analogue score for pain } \\
\hline & & $\begin{array}{c}\text { Group A } \\
(55)\end{array}$ & $\begin{array}{c}\text { Group B } \\
\text { (55) }\end{array}$ & $\begin{array}{c}\text { Control Group } \\
\text { (55) }\end{array}$ \\
\hline Baseline & $\mathrm{Me}$ & $44.38 \pm 14$ & $48.48 \pm 12.04$ & $49.32 \pm 3.05$ \\
\hline 3 Months & $\mathrm{Me}$ & $20.94 \pm 16.0$ & $28.85 \pm 15.46^{2}$ & $37.58 \pm 4.32$ \\
\hline
\end{tabular}

Figure 3: Patients with Significant Pain Relief in terms of Oswestry Disability Index

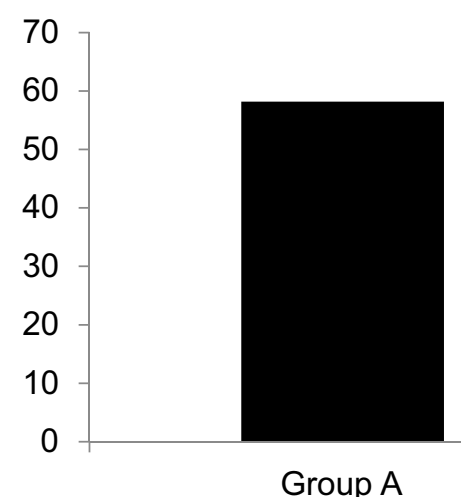

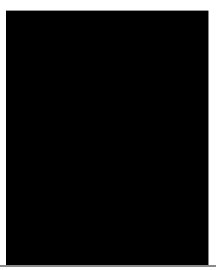

Group B

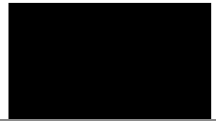

Control Group

Patients with Significant Pain Relief

\begin{tabular}{|c|c|c|}
\hline $\begin{array}{c}\text { Group A } \\
\text { (55) }\end{array}$ & $\begin{array}{c}\text { Group B } \\
\mathbf{( 5 5 )}\end{array}$ & $\begin{array}{c}\text { Control Group } \\
\mathbf{( 5 5 )}\end{array}$ \\
\hline 32 & 24 & 11 \\
\hline $58.18 \%$ & $43.64 \%$ & $20.00 \%$ \\
\hline
\end{tabular}




\begin{tabular}{|c|c|c|c|c|c|c|c|c|}
\hline & & & \multicolumn{2}{|c|}{ Successful Patients } & \multicolumn{2}{|r|}{ Failed Patients } & \multicolumn{2}{|r|}{ Total } \\
\hline Group A & \multicolumn{2}{|c|}{ Mean \pm SD } & \multicolumn{2}{|c|}{$34.68 \pm 12.27$} & \multicolumn{2}{|r|}{$6.64+7.82$} & \multicolumn{2}{|c|}{$22.95 \pm 17.50$} \\
\hline Group B & \multicolumn{2}{|c|}{ Mean \pm SD } & \multicolumn{2}{|c|}{$37.24 \pm 7.25$} & & $5.15 \pm 11.21$ & \multicolumn{2}{|c|}{$19.15 \pm 18.50$} \\
\hline Control Group & \multicolumn{2}{|c|}{ Mean \pm SD } & \multicolumn{2}{|c|}{$33.51 \pm 8.51$} & \multicolumn{2}{|r|}{$5.14 \pm 9.16$} & \multicolumn{2}{|c|}{$11.81 \pm 16.57$} \\
\hline \multicolumn{9}{|c|}{ Table-IIlb. Average relief per group in terms of oswestry disability index } \\
\hline & & \multicolumn{2}{|c|}{ Group A (55) } & \multicolumn{3}{|c|}{ Group B (55) } & \multicolumn{2}{|c|}{ Control Group (55) } \\
\hline & & Baseline & 3 Months & \multicolumn{2}{|c|}{ Baseline } & 3 Months & Baseline & 3 Months \\
\hline \multicolumn{2}{|l|}{ Employed } & $27.27 \%(15)$ & $36.36 \%(20)$ & \multicolumn{2}{|c|}{$29.09 \%(16)$} & $34.55 \%(19)$ & $23.63 \%(13)$ & $29.09 \%(16)$ \\
\hline \multicolumn{2}{|c|}{ Unemployed (due to pain) } & $10.91 \%(6)$ & $1.82 \%(1)$ & \multicolumn{2}{|c|}{$12.73 \%(7)$} & $7.27 \%(4)$ & $14.55 \%(8)$ & $9.09 \%(5)$ \\
\hline \multicolumn{2}{|c|}{ Housewife } & $27.27 \%(15)$ & $27.27 \%(15)$ & \multicolumn{2}{|c|}{$21.82 \%(12)$} & $21.82 \%(12)$ & $23.63 \%(13)$ & $23.63 \%(13)$ \\
\hline \multicolumn{2}{|l|}{ Retired (over 65) } & $34.55 \%(19)$ & $34.55 \%(19)$ & \multicolumn{2}{|c|}{$36.36 \%(20)$} & $36.36 \%(20)$ & $38.18 \%(21)$ & $38.18 \%(21)$ \\
\hline \multicolumn{2}{|l|}{ Total Patients } & $100 \%(55)$ & $100 \%(55)$ & \multicolumn{2}{|c|}{$100 \%(55)$} & $100 \%(55)$ & $100 \%(55)$ & $100 \%(55)$ \\
\hline
\end{tabular}

\section{DISCUSSION}

This randomised control trial compares patient outcomes in terms of pain relief and improvement in functionality at three months following application of the lumbar epidural injection using fluoroscopy and loss of resistance technique. Both group $A$ and group $B$ patients showed better results as compared to control group. While, group A showed the lowest means VAS for pain and ODI scores at 3 months and demonstrated greater average total relief when compared to other two groups, there was similar observation of 'mild pain' at 3 months in comparison to 'severe pain' at baseline in terms of VAS scores in both groups A and B. Similarly, on average patients in both groups $A$ and $B$ were experiencing 'moderate disability' at 3 months in terms of ODI as compared to 'severe disability' at baseline.

The results between groups $A$ and $B$ showed greatest divergence in terms of the proportion of respondents with significant relief when comparing both VAS for pain and ODI scores. The benchmark for significant pain relief was at least $50 \%$ improvement in pain and patients were regarded a success where they exhibited significant pain relief at 3 months. This standard is stricter than that used in previous studies. As pointed out by Carragee \& Cheng in their 2010 study on patient outcomes, the minimum clinically important difference for lower back pain problems that is, the absolute worst outcome that would be acceptable to patients, is 1 to 2 VAS points or an ODI score improvement of approximately 15 points for non-surgical intervention. ${ }^{8}$ The standard utilised in this study is more rigorous and robust, focusing on genuine and significant pain reduction amongst patients. Based on this standard, approximately $10 \%$ more patients in group $A$ as compared to group $B$ showed significant pain relief in terms of VAS for pain and roughly $15 \%$ more patients in group $A$ as compared to group B showed significant pain relief in terms of ODI score improvement. However, mixed results were obtained when patients in each of the three groups were further subdivided into successful and failed patients. Group B showed slightly better results amongst successful patients for average relief in terms of both VAS for pain and ODI. Similar findings were not observed for the failed patients category and group A patients under this head showed greater average relief in terms of VAS for pain and ODI.

It is one of the first studies to be focused entirely on patient outcomes as compared to needle placement in lumbar epidural injections both with and without image guidance. While superiority of lumbar epidural injection with fluoroscopy with regards to needle placement has been clearly established when compared with lumbar epidural injections using loss of resistance technique, the results of this study show that patient outcomes, that is, improvement in functionality and pain relief, may not be as different for the two techniques. As between patients that were given lumbar epidural injection using either technique, patients that were given the injection with fluoroscopy show slightly better results, but the difference in patient outcomes in terms of pain relief and functionality 
may not appear to be stark enough to warrant the additional costs association with such treatment using image guidance.

However, the findings of this study are not without limitations. Firstly, the sample size of this randomised control trial is small. While the results of this study were found to be statistically significant with a P-value of less than 0.05 , the study should be repeated using a larger sample to conclusively establish and confirm the findings. Secondly, this is a short-term study with findings as to patient outcomes restricted to the 3 month evaluation period used in this study. Despite the lumbar epidural injection being a short term treatment for lower back pain secondary to lumbar disc herniation and radiculopathy, a long-term follow-up study should be conducted to identify long-term efficacy of findings and implications of the treatment using both techniques. Thirdly, it should be noted that the inclusion criteria for the study did not differentiate between patients that were given the lumbar epidural injection for the first time or patients that were given an injection the second or third time. The follow-up study should differentiate between these two categories of patients and if included in the study, findings pertaining to patients that were given the injection again should be presented separately as well to allow for an additional level of analysis.

Keeping this in mind, the findings of this study provide at least an initial basis for conducting a cost-utility analysis of administering lumbar epidural injections using fluoroscopy or imaging intensifier. Group A patients showed definitively better results than the other two groups that were part of the study. This raises the question whether the difference in relief for Group A patients versus relief for Group B patients justifies the additional costs associated with administering lumbar epidural injections using fluoroscopy as compared to the cheaper loss of resistance technique. It should be noted here that it was not possible to attribute a numerical value for each of the costs associated with epidural injections using fluoroscopy that have been identified here.

It should also be noted that administering lumbar epidural injections using image guidance takes about twice as much time as administering the same using the loss of resistance technique. The most obvious cost associated with administering epidural injections using fluoroscopy is the cost of provision of the radiographer to the orthopaedic theatre. Furthermore, availability of the radiographer and schedule preparation is also an issue. Alongside this, using image guidance will also add to the infrastructural costs of the trust, adding to the bill the fixed cost of purchasing image intensifier machine for the theatre and variable utility costs associated with the regular use of the machine

In light of these costs, the results of this study support the view that the differences in patient outcomes in terms of pain relief and improvement in functionality are not significantly different as to warrant the use of fluoroscopy in administering lumbar epidural injections. The findings support the view that epidural injections using fluoroscopy are not sufficiently superior so as to be used as the preferred means of giving such treatment as compared to the loss of resistance technique. It is suggested here that the loss of resistance technique should be the first port of call when giving epidural injections to patients. Where patients do not show a satisfactory level of improvement, they may then be treated with a second lumbar epidural injection using image intensifier for better results. The findings of this study support the proposition that the significantly cheaper loss of resistance technique is an effective means of relieving lower back pain and therefore, should be used in preference to lumbar epidural injections using fluoroscopy at least for patients that are being given the injection for the first time. This will ensure the most cost and time effective utilisation of the limited resources available to the trust.

\section{CONCLUSION}

This randomised control trial study forms part of the sparse body of literature surrounding patient outcomes for both lumbar epidural injections with and without fluoroscopy. The results show that the although patients treated with epidural injections using fluoroscopy showed better 
results but in comparison the outcome in terms of pain relief and improvement in functionality at the end of three months in patients those had the lumbar epidural injection using loss of resistance technique was not far behind. There were also some mixed results where successful patients that were treated using loss of resistance technique actually showed greater average relief than patients that were treated using fluoroscopy. Therefore, these findings do not establish any clear level of superiority for administration of lumbar epidural injections using fluoroscopy over the loss of resistance method as it exists in studies that have examined the level of accuracy of needle placement for the two techniques.

\section{Copyright(c) 15 Nov, 2018.}

\section{REFERENCES}

1. Manchikanti L, Singh V, Cash K, Pampati VRT and Falco, FJE. A randomized, double-blind, active-control trial of the effectiveness of lumbar interlaminar epidural injections in disc herniation. Pain Physician 2014; 17 : E61-E74 ISSN 2150-1149.

2. Manchikanti L, Cash K, McManus CD, Pampati VRT and Benyamin R. Fluoroscopic lumbar interlaminar epidural injections in managing chronic lumbar axial or discogenic pain. J Pain Res. 2012; 5: 301-11. DOI: 10.2147/JPR.S32699.
3. Manchikanti L, Cash K, McManus CD, Pampati VRT and Benyamin R. A randomized, double-blind, activecontrolled trial of fluoroscopic lumbar interlaminar epidural injections in chronic axial or discogenic low back pain: Results of 2-year follow-up. Pain Physician. 2013; 16(5):E491-504.

4. Benyamin R, Manchikanti L, Parr AT, Diwan S, Singh V, Falco FJE, Datta S, Abdi S and Hirsch J. The effectiveness of lumbar interlaminar epidural injections in managing chronic low back and lower extremity pain. Pain Physician 2012; 15(4):E363-404.

5. Beliveau P. A comparison between epidural anaesthesia with and without corticosteroid in the treatment of sciatica. Rheumatol Phys Med 1971; 11(1):40-3.

6. Breivik $\mathrm{HH}$, Hesla PE, Molnar I, Lind B. Treatment of chronic low back pain and sciatica: comparison of caudal epidural injections of bupivacaine and methylprednisolone with bupivacaine followed by saline. Adv Pain Res Ther 1976; 1:927-32.

7. Carette S, Marcoux S, Truchon R, Grondin C, Gagnon $\mathrm{J}$, Allard $\mathrm{Y}$, et al. A controlled trial of corticosteroid injections into facet joints for chronic low back pain. N Eng J Med 1991; 325(14):1002-7.

8. Carragee EJ \& Cheng I. Minimum acceptable outcomes after lumbar spinal fusion. The Spine $\mathrm{J}$ 2010; 10(4): 313-20. DOI: 10.1016/j.spinee.2010.02.001

\begin{tabular}{|c|c|c|c|}
\hline \multicolumn{3}{|c}{ AUTHORSHIP AND CONTRIBUTION DECLARATION } \\
\hline Sr. \# & Author-s Full Name & Contribution to the paper & Author=s Signature \\
\hline 1 & Athar M Siddqui & Study design, Data collection. & $\mid$ \\
\hline 2 & Umar Zia Khan & Manuscript writing. \\
\hline
\end{tabular}

